\title{
Le Sixième Sommeil
}

\author{
Geon Ho Bahn \\ Department of Psychiatry, Kyung Hee University School of Medicine, Seoul, Korea
}

잠

반 건 호

경희대학교 의학전문대학원 정신건강의학교실
저 자: Bernard Werber (옮긴이 전미연)

출판사: (번역판) 열린책들

출간연도: (번역판) 2017. 5. 30. (ISBN13: 9788932918372)

꿈을 꾸는 이유는 주간에 있었던 사건이나 기억의 잔재, 수면 중 감각 변화에 대한 반응, 소망 충족, 그리고 예지몽을 들 수 있다. 정신분석에서는 무의식적 소망 충족을 중요하게 생각하였고, 꿈을 통해 무의식에 접근할 수 있을 것으로 판 단하여 꿈 분석에 많은 노력을 기울였다. 서평을 쓰고 있는 저자는 이러한 정신분석적 꿈 이론 외에 잘 알려지지 않은 꿈의 기능 중 하나인 ‘예지몽'에도 관심이 있었다. 예지몽은 과거는 물론 미래에 대한 인간의 호기심을 불러 일으키는 매우 매력적인 주제이다. 일부 정신과 의사 중에는 전생을 보는 꿈 분석을 시도하기도 한다. 타임머신이 공상과학소설 이나 $\mathrm{SF}$ 영화의 단골 주제로 등장하는 것도 미래에 대한 인 류의 호기심과 앞날의 불확실성에 대한 불안 때문일 것이다. '당신 거기 있어 줄래요', ‘종이 여자' 등 과거와 현재 사이에 소통이 가능해지는 기욤 뮈소(Guillaume Musso)의 소설들, 김은희 작가의 드라마 ‘시그널', 김은숙 작가의 ‘도깨비' 등 흥행 돌풍을 일으키고 있는 작품들 역시 현재 살고 있는 인 물들이 과거와 미래를 오가는 주제이며, 이들 역시 미래에

Address for correspondence: Geon Ho Bahn, MD

Department of Psychiatry, Kyung Hee University School of Medicine, 23 Kyungheedae-ro, Dongdaemun-gu, Seoul 02447, Korea

Tel: +82-2-958-8556, Fax: +82-2-957-1997, E-mail: mompeian@khu.ac.kr

This is an Open Access article distributed under the terms of the Creative Commons Attribution Non-Commercial License (http://creativecommons.org/licenses/by-nc/4.0) which permits unrestricted non-commercial use, distribution, and reproduction in any medium, provided the original work is properly cited.
대한 궁금증을 자극하는 것이며, 앞날에 대한 예언을 기대하 는 인간 속성을 충족시키는 주제이다.

베르나르 베르베르(Bernard Werber)가 의도한 것이 이러 한 주제를 설명하고자 한 것이었는지는 모르겠으나, 저자는 베르나르 베르베르의 최신작 '잠'을 읽으며 예지몽 개념에 대한, 과학적 근거는 미약하지만 '허구적' 근거라도 찾게 된 것이 매우 기쁘며, 이 서평을 쓰게 된 이유 중 하나이기도 하 다. '타나토노트'와 '천사들의 제국'을 통해 사후세계를 보여 주고, '파피용'이나 '카산드라의 거울'에서는 인류의 미래에 대해 근거 중심적인 듯 보이면서 완전히 허구적이라고도 할 수 없는 만족할 만한 근거를 제공하는 베르베르 작가에게 항상 고마움을 느낀다. 더구나 그의 허구는 재미가 있고 건 강한 중독성까지 있다.

서평에서는 대개 책 내용을 소개하는 편이지만 신간 소설 이라는 특성이 있으므로 가급적 내용 소개는 짧게 하겠지만, 작가가 소설에서 인용하는 많은 내용들은 실제 과학적 근거 를 갖는 것이고 알려진 부분들이므로 그런 부분들도 간단히 소개하려고 한다. 소설의 내용은 다음과 같다.

수면의학자인 카롤린 클라인은 지금까지 알려진 수면 단 계 이외의 과정을 밝혀내려고 수십 년째 연구를 계속하던 중, 어느 날 피험자가 실험 중 사망한 뒤 실종된다. 아들 자 크 클라인(Jacques Klein) 역시 의과대학을 졸업하고 수면의 학연구자가 된다. 사라진 어머니를 찾기 위해 노력하던 중 꿈 속에서 미래의 자신을 만나고, 말레이지아 세노이족을 찾 아나선다. 결국 아무도 해내지 못한 6단계 수면에 이르는 법 을 찾아내고 어머니를 구해낸다.

작가는 수면 단계를 실제 수면학자들이 제시하는 단계를 거의 그대로 인용하고 있다. 수면의학에서는 수면 과정을 입 면 단계, 수면 1 4단계, 렘수면(REM sleep, 역설수면)으로 
분류한다. 작가는 렘수면을 5 단계 수면이라고 제시하였다. 그러나 작가가 5단계 수면을 1 4단계에서 이어지는 깊은 수 면으로 이해한 것은 아니라는 것은 '잠 1권 54쪽' 수면 곡선 을 보면 알 수 있다. 각 수면 단계별 뇌파 변화도 정확하게 기술하였다.

소설 속에 등장하는 말레이지아의 세노이족은 실제 존재 하는 부족이다. 로버트 울프(Wolff 2001)는 세노이족과 십여 년간 함께 생활하면서 그들의 삶과 철학을 기술한 책을 출간 하였다. 세노이족은 정신병이나 신경증이 없는 종족이다. 꿈 은 두려움의 근원이므로 이야기하면서 해결한다. 매일 아침 부족민 전체가 한 곳에 모여 간밤에 꾼 꿈 이야기를 공유한 다. 꿈은 두려움을 주기도 하지만 집단이 모이면 해결책을 찾을 수 있다. 이들의 집단 토의 방식 중 저자가 흥미롭게 생 각한 것 중 하나는 그들이 꿈을 공유하는 방식이 무의식적 또 는 의식적 불안을 해결하는 데 매우 유용하다는 것이다. 예를 들어, 꿈 속에서 옆집 여자와 성행위를 한 이웃집 남자는 옆 집 여자에게 꿈 이야기를 하고 고맙다는 선물을 한다는 것이 다. 불륜에 대한 미안함과 불안을 공개하고 사과하며 감사함 으로써 오히려 불안을 해소할 수 있다. 전날 꿈에서 마을의 누군가와 싸워서 상처를 입혔다면 다음 날 그 사람을 찾아가 꽃을 주며 사과한다. "세노이족 사회는 즐겁고 평화롭고 안 정된 공동체이다. 강간이나 범죄, 자살, 정신병이 없는 곳이 다. 아이들은 가족과 타인과 자연을 존중하라는 교육을 받으 며 자란다. 미래를 두려워하지도 않는다. 꿈속에서 어렴풋이 접하기 때문이다. 자연에 대한 두려움도 없다. 꿈 속에서 자 연과 화해하기 때문이다"(잠 1권, 283 284쪽).

소설 속 인물 중 프랑키가 않고 있는 기면병의 원인 중 하 나로 소개한 유전자 HLA-DQB1 0602는 탈력발작형 기면병 환자의 $90 \%$ 정도에서 확인되는 유전자이며 임상 현장에서 생물학적 지표로 사용된다.

Science 학술지에 발표된 Horikawa 등(2013)의 연구는 큰 주목을 받았다. 연구자들은 수면 중인 피험자의 뇌파를 연속 측정하면서 렘수면에 돌입한 뒤 꿈을 꾸는 것을 확인하고 렘수면 직후 피험자를 깨워서 꿈을 기억하게 한다. 꿈 내용 과 뇌파 변화의 관련성을 분석하면 꿈 속 인물이나 사물과 관련된 뇌파 파형을 찾아낼 수 있는 것이다. 즉, 이러한 자료

a“작가가 REM 수면(역설 수면) 단계를 굳이 따로 숫자화시켜 5단 계로 구분한 것은 이 단계의 특성을 강조하기 위해서라고 이해하 였다. 소설 내용 중 중요한 의미를 갖는 자각몽을 꾸는 단계이니 아마도 이 단계를 숫자로 분명하게 표시해 강조하고 싶었을 것이다. 소설 독자들은 수면의학 전공자가 아니기 때문에 명확히 구분해주 는 것도 필요했을 것이므로 그대로 번역하였다." (번역자인 한국외 국어대학교 통역대학원 전미연 교수와의 개인적 소통).
가 축적되면 뇌파 기록만으로 꿈을 꾼 사람의 꿈 내용을 재 현해 낼 수 있다는 것이다.

본 소설 속에서는 Horikawa 등(2013)의 연구보다 진일보 한 세계가 펼쳐진다. 즉, 꿈꾸는 당사자가 우리가 알고 있는 1 4단계 수면 및 렘수면 이외의 심층단계를 경험할 수 있도 록 한다는 것이다. 이를 위해 고안한 것이 6단계 수면이다. 6 단계 수면에서는 뉴론 하나하나를 확인할 수 있으며, 우리가 무의식이라고 지칭하는 추상적 개념을 물리적이고 정량적, 정성적 존재로 접하게 된다. 6 단계 수면으로 유도하는 물질 은 '만드라고나'와 '벨라돈나'이며, 6 단계에서 정상으로 돌아 오는 데 필요한 해독제는 '다투라'와 '사리풀'이다. 안타깝게 도 이들 물질의 혼합비율은 베르베르 작가의 영업비밀인 듯 공개되지 않았다. 6단계에 도달하려면 이들 물질 이외에도 아톤(Aton)이 필요하다. 아톤은 '자연적인 꿈속 수면 시간 승강기(Ascenseur Temporel Onirique Naturel)'의 줄임말이 다. 우리가 알고 있는 것처럼 꿈의 세계에서는 시간과 공간 을 초월한다. 아톤을 이용하면 자신의 꿈속에서 자신의 과거 와 미래를 오갈 수 있는 것이다. 아톤은 일종의 심리적 미장 아빔(mise en abyme $)^{\mathrm{b}}$ 기법을 이용하여 완성한다. 이 기법은 한 작품 안에 다른 작품을 집어 넣는 예술적 기법이다. 저자 의 성(family name), 클라인(Klein)이 시간승강기를 완성하 는 백미이다. 미장아빔 기법을 통해 완성되는 '클라인의 병' 이 시간승강기이다. 만드는 법은 특정 뉴런을 다른 뉴런들과 이어주는 시냅스와 분리시킨 뒤 신경세포막을 둥그런 공처 럼 만들어 놓고 항아리처럼 모양을 잡는다. 그리고 유리세공 을 하듯 항아리 끄트머리를 당겨 주둥이를 만들고 돌출한 주둥이 부분을 길게 쭉 늘여서 항아리 옆구리에 박아 끼운 다. 아래쪽 끄트머리를 쪽 벌려서 항아리 밑바닥과 합쳐져 통하게 만들면 클라인의 병이 탄생한다. '클라인의 병'에서 는 시작과 끝이 없고, 시공을 초월하며 내부와 외부의 구분 이 없고, 현재에서 과거를 볼 수 있고 미래와도 연결된다. 뉴 런 하나를 클라인의 병으로 바꾸는 것이 아톤의 핵심 원리 이다(잠 2권, 276 280쪽).

소설 초반에 주인공이 친구의 불안함을 해결해주는 장면 이 나온다. 소위 정신분석적 꿈의 해석과 능동적 꿈꾸기 원 리를 이용한다. 개인이 각자 ‘클라인의 병’을 구성하는 것이 가능해진다면 정신분석의 임무는 막을 내리게 될 것이다. 베 르나르 베르베르는 ‘클라인의 병’을 완성했을까?

우리는 매일 밤 잠을 잔다. 가끔 낮잠도 즐긴다. 잠들기 전 항상 기억해 둘 것이 있다. 책 서두와 말미에 나오는 것처럼 꿈 속에서 갑자기 "20년 뒤의 나를 만나면 무엇을 물어볼 것

'디에고 벨레스케스의 그림 '시녀들(Las Meninas)' 속의 거울 속 화 가의 모습이나, 영화 '인셉션(Inception)' 참조. 
인가?” 그리고 하나 더 물어본다면, "20년 뒤에는 정신분석이

어떻게 될까요?"

\section{REFERENCES}

Horikawa T, Tamaki M, Miyawaki Y, Kamitani Y. Neural decoding of visual imagery during sleep. Science 2013;340:639-642.

Wolff R. Original Wisdom: Stories of an Ancient Way of Knowing; Rachester, VT: Inner Traditions;2001. 